\title{
CLINICAL STUDIES OF ISOLATED DISC RESORPTION IN THE LUMBAR SPINE
}

\author{
R. M. VENNER, H. V. CROCK \\ From St Vincent's Hospital, Melbourne
}

\begin{abstract}
Low lumbar pain with radiation into the leg is a common symptom pattern caused by a number of pathological processes. Isolated disc resorption is one such entity which can be readily identified and is amenable to surgical treatment. This study consisted of two groups of patients. Group I were 50 patients suffering from isolated disc resorption at L5-S1 with ill-defined low backache extending into the buttocks and down one or both legs, but not into the feet. Clinical signs of nerve root dysfunction were found in 16 per cent of patients. Radiographic changes with loss of disc height, facet over-riding and intrusion into the nerve root canal and intervertebral foramen were common and frequently associated with sclerosis of the vertebral end-plate.

Group II were a series of 45 patients with isolated disc resorption independently reviewed an average of 45 months after surgical decompression of the S1 (98 per cent) or lower lumbar nerve roots. Based on objective grading by the clinician and subjective assessment by the patient complete success was achieved in 62 per cent of the patients and partial success in 24 per cent. Provided there is full appreciation of the pathological anatomy, strict diagnostic criteria and meticulous surgery, decompression of the nerve root canal is a useful surgical procedure in severely disabled patients suffering from isolated disc resorption.
\end{abstract}

The term isolated disc resorption was first used by Crock (1970) to describe the clinical symptoms and signs and radiological findings of a condition characterised by loss of disc height usually at the L5-S1 junction. Williams (1932) described the condition but failed to recognise its importance and his work was largely overshadowed by the classic paper on disc prolapse by Mixter and Barr (1934). In a second paper on this subject Crock (1976) discussed it as an important cause of nerve root canal stenosis in the lumbar spine.

With the exception of these three papers this clinical entity has received scant attention until the recent publications of Burton et al. (1979), KirkaldyWillis and Hill (1979) and Lancourt, Glenn and Wiltse (1979). These authors recognise the effect that loss of disc height has on the posterior apophysial joints and, in particular, the subsequent diminution in the size of the nerve root canal.

Radiological findings are the key to the diagnosis of this condition. Williams (1932) found narrowing of the intervertebral disc space in 59 out of 80 patients presenting with backache or sciatica, the majority of these being young adults. Subsequently he reviewed 1500 radiographs and apart from those with sacralisation of the fifth lumbar vertebra, in whom the disc space is congenitally narrow, only patients with backache were noted to have loss of L5-S1 disc height.

Crock (1970) added to this description, pointing out that sclerosis of the vertebral end-plates and intrusion of the posterior facet joints into the lumbar nerve root canals (Fig. 1) were also important radiological features. Torgerson and Dotter (1976) have shown recently that narrowing of more than two millimetres in the intervertebral disc is associated with a significant incidence of low backache in the young age group of $\mathbf{4 0}$ to 49 years. Forty-eight per cent of those who complained of backache had narrowing of the intervertebral disc space compared with six per cent in those who were free of symptoms.

\section{SURGICAL TECHNIQUE}

If the various factors contributing to the spinal nerve canal stenosis are fully appreciated, as described by Crock in the accompanying article, then the planning of the surgical decompression can be logically organised. The technique can be used at any level but the description given here is of decompression of the L5-S1 nerve root.

The S1 spinal nerve canal is deroofed by total excision of the ligamentum flavum, including the bony ridge on the under surface of the lamina, partial facetectomy of the inner margin of the inferior facet of L5, and partial facetectomy of the medial and apical portions of the S1 facet, thereby relieving the mechanical obstruction which affects both the $\mathrm{S} 1$ and the L5 nerve roots. In the process of excising the medial margin of the $\mathrm{S} 1$ facet and its apex, it is possible to demonstrate the obstruction of the intervertebral veins and internal venous plexus and to observe the refilling of these vessels when the surgical dissection has been completed.

In some instances excision of the bony ridge and apical attachment of the ligamentum flavum can only be achieved after excision of the central arch of the lamina of L5. When this becomes

R. M. Venner, FRCS Ed, Consultant Orthopaedic Surgeon, Western Infirmary, Glasgow G11 6NT, Scotland.

H. V. Crock, MD, MS, FRCS, FRACS, Senior Orthopaedic Surgeon and Professorial Associate, St Vincent's Hospital, University of Melbourne, Victoria Parade, Fitzroy, Victoria 3065, Australia.

Requests for reprints should be sent to Mr R. M. Venner.

(C) 1981 British Editorial Society of Bone and Joint Surgery 0301-620X/81/4106-0491 $\$ 2.00$ 
necessary care is taken to preserve the pars interarticularis of this lamina on both sides, leaving it smooth and coating the cut bony surface with bone wax.

Very rarely is it necessary to interfere with the floor of the S1 spinal nerve canal in cases of isolated disc resorption. Occasionally a subrhizal vertebral end-plate sequestrum will be found and this obstruction should be removed from beneath the S1 nerve root.

\section{MATERIAL AND METHODS}

Ninety-five patients with isolated disc resorption were reviewed. These were divided into two groups.

Group $I$ consisted of 50 consecutive patients who had presented to the private practice of one of us (HVC) between January 1978 and September 1979 and they were reviewed independently by the other author (RMV). A careful history was recorded which included details of the patients' work record, an assessment of functional disability and notes on previous treatment. Routine physical examinations were performed and tests carried out for the non-organic signs described by Waddell et al. (1980). At the end of each interview, recent radiographs in two planes of the lumbosacral region were examined and special. note made of the coned view of the lumbosacral junction. The disc height was measured at its anterior and posterior margins. These results were recorded with the other radiological signs of isolated disc resorption (Table I).

The group consisted of 30 men and 20 women with average ages of 41 and 38 years respectively; the age range was from 16 to 67 years. Fifty-two per cent of the patients were involved in a workers' compensation claim. Thirty-eight per cent had lost more than one month from work in the preceding year because of disabling symptoms arising from the condition.

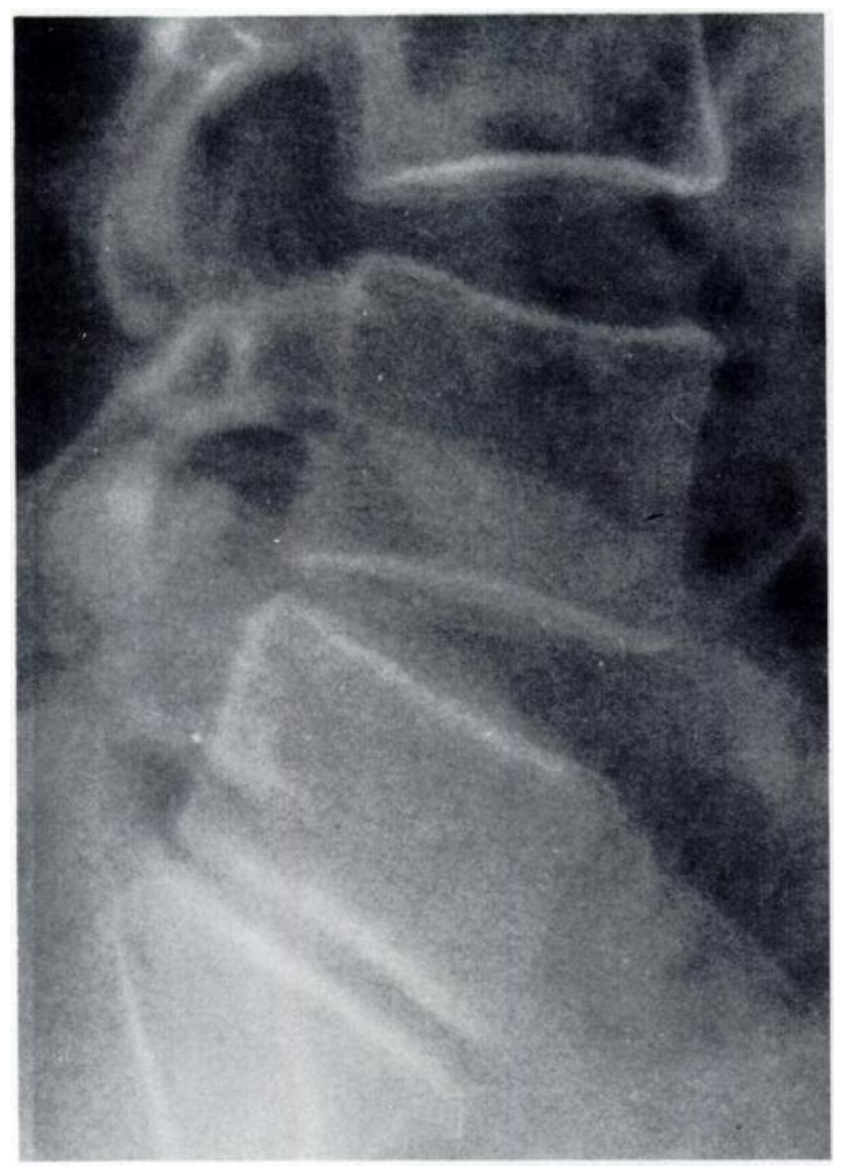

Fig. 1

A lateral radiograph of the lumbar spine of a 48-year-old man showing the classical features of an isolated disc resorption at the lumbosacral junction.
Table I. Radiological signs of isolated disc resorption

1. Intervertebral disc space $<15$ millimetres anteriorly $<5$ millimetres posteriorly

2. Sclerosis of the vertebral body

3. Subluxation of the facet joint

4. Intrusion of the facet joint into the L5-S1 intervertebral foramen.

Group II was the majority of the 58 patients who presented to HVC between 1968 and 1979 with isolated disc resorption and sufficient disability to warrant surgical intervention; the appropriate spinal nerve roots had been decompressed (by HVC). Ninety-five per cent of these patients had been treated in a private clinic, the remainder seen as public patients. All patients were asked to attend for independent interview and examination by RMV, who had no knowledge of their clinical condition before or after operation.

Forty-five patients ( 78 per cent) were able to attend for interview. Two patients had died of unrelated causes, one an accidental death in a road traffic accident and the other as a result of a myocardial infarction. Three patients refused to attend because of the distance involved-two lived in Tasmania and one in New South Wales. Eight patients could not be traced.

This group contained 22 men and 23 women whose average age at operation was 45 years and 42 years respectively (range 20 to 74 years). The average time since operation was 45 months ranging from 6 months to 144 months, only four patients being reviewed within 12 months of operation.

At review, a full history and examination of each patient was carried out and six separate criteria were used to judge the success or failure of the operation. The patient was asked "was the operation worthwhile?"; if he was unable to make up his mind this was counted as "no". He was also asked if he was significantly restricted in any of 10 simple activities of everyday living (such as walking, standing and lifting heavy weights), the number of activities restricted-from 0 to 10-giving a measure of the severity of functional disability. This estimate of the final disability at the time of review was compared with the patient's memory of his disability before operation. Improvement of three or more points on this scale was taken to indicate success.

The patient's work record was noted both before and after operation. Forty-one patients ( 91 per cent) had either lost six weeks from work or, in the case of housewives, required help with all but the lightest tasks for one year before operation. Many patients had lost their jobs or had had to change their occupations because of their symptoms. Against this background it was decided to accept surgical success only if the patient had returned to his or her previous occupation, or to a modified job. In the case of housewives, a positive surgical result was recognised if she was able to carry out her household duties to the full or if she was limited only in tasks such as moving furniture or carrying heavy loads.

Almost all the patients complained to a greater or lesser extent of backache. Before the operation patients had been informed that complete relief of pain was unlikely but that significant reduction in pain was anticipated for the majority. At review the patients were asked to compare their present degree of pain with that which existed before operation: complete or partial relief was considered a successful result; pain that was not relieved or was made worse was deemed a failure. Pain in the legs and buttocks was treated in exactly the same way as backache.

The final criterion used was the independent observer's objective assessment at review. The results were expressed as good, fair and poor using the grading of Spangfort (1972). A good result was defined as virtually no pain and no alteration in life style. A fair result was defined as occasional pain only, which was relieved quickly by short-term bed rest and analgesics and requiring only minor alteration in activities. A poor result was indicated by frequent or continuous 
backache or pain in the legs with the need for chronic narcotic treatment or an additional operation. It was hoped that this standardised grading would aid comparison with other surgical series. Patients with either a fair or poor result were considered failures in the final analysis. The assessment also incorporated the non-organic physical signs described by Waddell et al. (1980) in an attempt to verify the true physical impairment while minimising the inappropriate or magnified element of the complaints.

Thus all patients had a six-point assessment of their surgical result: patient's evaluation, functional disability, work status, relief of backache, relief of pain in the legs and observer's assessment. These criteria were analysed individually and collectively. If all six criteria were positive the operation was considered to be a complete success. Three to five criteria positive was taken to be a partial success. If two or less of the six criteria were positive the operation was graded a failure.

\section{RESULTS}

\section{Group I}

Ninety-four per cent of these patients complained of low lumbar pain, and 48 per cent noted radiation of pain to one or both buttocks; 76 per cent had pain in one or both legs, and 50 per cent complained of paraesthesia. Only eight per cent reported an exacerbation of their pain on coughing, but 18 per cent gave a history of increasing leg pain or paraesthesia on walking distances up to 500 yards. Some patients had weakness and occasional dragging of the feet or difficulty in standing, but these symptoms settled on resting, usually by sitting. Ninetyfour per cent had lumbar tenderness, but only eight patients had reduced lumbar movement as defined by Moll and Wright (1976).

Signs of root irritation, as evidenced by limited straight leg raising, painful bowstring test or sciatic nerve tenderness, were detected in only six per cent; and reduced nerve conduction, indicated by wasting, motor weakness, sensory abnormality or reflex depression, in 16 per cent. One or both ankle jerks were absent in 10 per cent.

Radiological findings. Measurements of the L5-S1 disc space are shown in Table II. Only one patient had measurements which approached the normal anterior and posterior heights of the disc as defined by Brav, Bruck and Fruchter (1942). Crock in 1970 described the narrowing between the vertebral end-plates of the disc space as being parallel, but in this series only seven patients (14 per cent) had a difference of less than three millimetres between the measurements made at the anterior and posterior margins of the invertebral body. Fifty per cent showed moderate or severe sclerosis of the vertebral end-plates, and 70 per cent had hypertrophy or deformity of the posterior facet joints (Fig. 1).

\section{Group II}

Before operation 44 patients had backache and 43 had pain in the legs extending to the knee or below. One patient had leg pain alone and two patients had backache as their only presenting symptom. When directly questioned 38 patients ( 84 per cent) felt the operation had been worthwhile (Table III). Of the remaining seven, only two patients definitely felt the operation was not worthwhile, while the remaining five were unable to give a definite opinion and were deemed to be failures.

Loss of function is usually the main indication for operation, particularly if the patient's livelihood is threatened. Any change in disability can be used as an assessment of success or failure. Thirty-two patients ( 71 per cent) improved from an average disability score before operation of 7.3 to a score of 1.5 , and were therefore considered to have good results; the remaining patients had improvement in less than three of the 10 items of function. No patient was worse after operation on this scoring system, and those who failed to improve their function had no worse a score before operation than the patients who improved.

The patient's ability to return to work is probably the easiest criterion to assess but the hardest to interpret. The issue is frequently clouded by compensation claims, industrial or otherwise. In this group 19 patients (42 per cent) had a claim pending or had had a claim settled. Despite this adverse factor the results were encouraging. Seventy-five per cent of patients returned to gainful employment, either their original occupation (69 per cent) or a modified job (six per cent) to suit their residual disability.

Low backache was the most consistent feature of isolated disc resorption, though not always the most disabling. Eighty-four per cent of patients gained

Table II. Height of the L5-S1 intervertebral disc (50 patients)

\begin{tabular}{|l|c|c|c|c|c|}
\hline \multirow{2}{*}{} & \multicolumn{3}{|c|}{ Anterior height } & \multicolumn{2}{c|}{ Posterior height } \\
\cline { 2 - 6 } & $>10 \mathbf{~ m m}^{*}$ & $\mathbf{1 0}-\mathbf{5} \mathbf{~ m m}$ & $<\mathbf{~} \mathbf{~ m m}$ & $>\mathbf{5} \mathbf{~ m m}$ & $<5 \mathbf{~ m m}$ \\
\hline Male & 7 & 20 & 3 & 5 & 25 \\
Female & 3 & 14 & 3 & 4 & 16 \\
\hline Totals & 10 & 34 & 6 & 9 & 41 \\
\hline
\end{tabular}

*In only one patient was the height more than 15 millimetres

Table III. Success rate of the operation for isolated disc resorption based on six criteria (45 patients)

\begin{tabular}{|c|c|c|c|}
\hline Criteria & $\begin{array}{l}\text { Success rate for } \\
\text { each individual } \\
\text { criterion } \\
\text { (per cent) }\end{array}$ & \multicolumn{2}{|l|}{$\begin{array}{l}\text { Overall success rate } \\
\text { of operation } \\
\text { (per cent) }\end{array}$} \\
\hline $\begin{array}{l}\text { Operation considered } \\
\text { "worthwhile" }\end{array}$ & 84 & $\begin{array}{l}\text { Complete success } \\
\text { ( } 6 \text { criteria) }\end{array}$ & \\
\hline $\begin{array}{l}\text { Functional disability } \\
\text { reduced }\end{array}$ & 71 & & \\
\hline Return to work & 78 & $\begin{array}{l}\text { Partial success } \\
\quad(3-5 \text { criteria) }\end{array}$ & 24 \\
\hline Relief of backache & 84 & & \\
\hline $\begin{array}{l}\text { Relief of pain in the } \\
\text { legs }\end{array}$ & 91 & $\begin{array}{l}\text { Failure } \\
\qquad(<3 \text { criteria })\end{array}$ & 14 \\
\hline $\begin{array}{l}\text { Observer's } \\
\text { assessment "good" }\end{array}$ & 71 & & \\
\hline
\end{tabular}


significant or complete relief of backache and were therefore considered operative successes. The remaining 16 per cent were no better although only two patients were worse. At review 39 had complete or considerable relief of their leg pain and none had any objective evidence of nerve root irritation or compression signs to suggest residual nerve root dysfunction.

The observer's grading (Spangfort 1972) found good results in 32 patients ( 71 per cent), fair in eight (18 per cent) and poor in five (11 per cent).

There was a high level of correlation between these six criteria for a successful surgical result. Twenty-eight patients were successful in all six criteria and were graded a complete success. Eleven patients were generally satisfied with the outcome on three to five criteria, the most common causes of failure being no reduction of disability, a fair or poor result on the observer's assessment and failure to return to gainful employment. The remaining six patients were considered to be failures. It appeared that these patients had psychological problems but, in this retrospective study it was impossible to say whether these predated the operation or were a result of its failure; four of this group were, or had been, involved in unsatisfactory compensation claims. Careful selection of patients for operation taking some account of psychological factors may therefore be the most expedient way of improving results.

Four patients required a further operation. In three, L5-S1 anterior interbody fusion was performed: two had gained no benefit from the decompression of the root canal and were therefore deemed complete failures; one had had four years of complete relief of symptoms and was therefore considered a success. The fourth patient, who required a further decompression of the root canal, had had 11 years of complete relief, and her second operation brought a further total recovery.

This work was supported by funds granted by the Sir William Angliss Trust, the William Buckland Foundation and Mr Joseph Wren. We are deeply indebted to these donors and also to Mr Peter Norris and Mr Hugh Williamson for their constant help. REFERENCES

Brav EA, Bruck S, Fruchter JM. A roentgenologic study of low back and sciatic pain. AJR 1942;48:39.

Burton CV, Heithoff KB, Kirkaldy-Willis W, Ray CD. Computed tomographic scanning and the lumbar spine. Part II. Clinical considerations. Spine 1979:4:356-68.

Crock HV. A reappraisal of intervertebral disc lesions. Med J Aust 1970;1:983-9.

Crock HV. Observations on the management of failed spinal operations. J Bone Joint Surg [Br] 1976: 58-B: 193-9.

Kellgren JH. Sciatica. Lancet $1941 ; \mathbf{i}: 561-4$.

Kirkaldy-Willis W, Hill RJ. A more precise diagnosis for low back pain. Spine 1979:4:102-9.

Kulak RF, Shultz AB, Belytschko T, Galante J. Biomechanical characteristics of vertebral motion segments and intervertebral discs. Orthop (lin North Am 1975;6:121-33.

Lancourt JE, Glenn WV Jr, Wiltse LL. Multiplanar computerized tomography in the normal spine and in the diagnosis of spinal stenosis: a gross anatomic-computerized tomographic correlation. Spine 1979;4:379-90.

McCulloch JA. Chemonucleolysis. J Bone Joint Surg [Br] 1977; 59-B: 45-52.

Mixter WJ, Barr JS. Rupture of the intervertebral disc with involvement of the spinal canal. $N$ Engl J Med 1934; 211: 210-5.

Moll J, Wright TV. Measurement of spinal movement. In: Jayson M, ed. The lumbar spine and back pain. London: Sector Publishing Ltd, 1976; 93-112.

Schmorl G, Junghanns H. The human spine in health and disease. Translated by Wilk SP, Goin LS. New York: Grune \& Stratton. 1959:38. Spangfort EV. The lumbar disc herniation. Acta Orthop Scand 1972;Suppl:142.

Stauffer RN, Coventry, MB. Posterolateral lumbar spine fusion: analysis of Mayo Clinic series. J Bone Joint Surg [Am] 1972;54-A:1195-204.

Torgerson WR, Dotter WE. Comparative roentgenographic study of the asymptomatic and symptomatic lumbar spine.J Bone Joint Surg [Am] 1976:58-A:850-3.

Waddell G, McCulloch JA, Kummel E, Venner RM. Nonorganic physical signs in low-back pain. Spine 1980:5:117-25.

Williams PC. Reduced lumbosacral joint space: its relation to sciatic irritation. JAMA 1932;99:1677-82. 